\title{
Transfer of TLC Screening Methods to Quantitative HPTLC-Densitometry Methods for Pharmaceutical Products Containing Amlodipine Besylate, Cefpodoxime Proxetil, Cetirizine 2HCl, Diclofenac Sodium, Efavirenz, Mefenamic Acid, and Atovaquone + Proguanil HCl
}

\author{
B. Zeng, Y. Gu and J. Sherma* \\ Department of Chemistry, Lafayette College, Easton, PA, USA
}

Received: 25 July 2018; accepted: 25 July 2018

\begin{abstract}
Transfer of seven thin-layer chromatography (TLC) Global Pharma Health Fund E.V. Minilab protocols for screening counterfeit pharmaceutical products in the field to quantitative high-performance TLC (HPTLC)-densitometry methods was performed using a model process published previously. The developed and validated methods for tablets containing amlodipine besylate, cefpodoxime proxetil, cetirizine $2 \mathrm{HCl}$, diclofenac sodium, efavirenz, mefenamic acid, and atovaquone + proguanil $\mathrm{HCl}$ involved the use of only relatively inexpensive and nontoxic solvents, Merck KGaA Premium Purity HPTLC silica gel $60 \mathrm{~F}_{254}$ plates, semi-automated sample and standard solution application with a CAMAG Linomat 4, and automated densitometry with a CAMAG Scanner 3 for detection, identification, and quantification. In addition, previously transferred HPTLC-densitometry methods for azithromycin and for cephalexin were used to analyze a new product of each drug to demonstrate the applicability of the methods.

Keywords: Amlodipine besylate, cefpodoxime proxetil, cetirizine $\mathrm{HCl}$, diclofenac sodium, efavirenz, mefenamic acid, atovaquone + proguanil $\mathrm{HCl}$, azithromycin, cephalexin, thin-layer chromatography, TLC, densitometry, counterfeit drug analysis
\end{abstract}

\section{Introduction}

A model process was previously developed [1-3] for transferring visual, semiquantitative thin-layer chromatography (TLC) screening methods for pharmaceutical products with quality defects in the Global Pharma Health Fund E.V. (GPHF) Minilab manual [4] to quantitative high-performance TLC (HPTLC)-densitometry methods. An earlier study in the literature [5] described the application of this model process to antimicrobial and antituberculosis products containing cefixime, cefuroxime axetil, cephalexin $\cdot \mathrm{H}_{2} \mathrm{O}$, ciprofloxacin $\mathrm{HCl}$, levofloxacin, and metronidazole. In this article, the application of the transfer process is extended by seven products containing eight important drugs of different types: amlodipine besylate (calcium channel blocker, CAS No. 111470-99-6), cefpodoxime proxetil (antibiotic, CAS No. 87239-81-4), cetirizine 2 $\mathrm{HCl}$ (antihistamine, CAS No. 83881-52-1), diclofenac sodium (nonsteroidal anti-inflammatory, CAS No. 15307-79-6), efavirenz (HIV antiviral, CAS No. 154598-52-4), mefenamic acid (nonsteroidal antiinflammatory, CAS No. 61-68-7), and atovaquone (antifungal and anti-parasite, CAS No. 95233-18-4) + proguanil $\mathrm{HCl}$ (antimalarial, CAS No. 637-32-1). In addition, two previously transferred HPTLC-densitometry methods for the antibiotics azithromycin dihydrate [6] and cephalexin [5] were successfully applied to analyze a new product of each drug to demonstrate their applicability.

\section{Experimental}

Standard and Sample Preparation. Standard and sample solution preparation was carried out as described in the model

* Author for correspondence: shermaj@lafayette.edu process [1-3] unless otherwise specified. Standards, tablets ground using mortar and pestle, and capsule contents were dissolved in their respective solvents with the assistance of $10 \mathrm{~min}$ magnetic stirring, followed by $10 \mathrm{~min}$ sonication. Sample stock solutions were syringe filtered to remove undissolved excipients before further dilution or direct application. Dilutions were made using appropriate volumetric flasks, volumetric pipets, and measuring pipettes if necessary. Solutions were stored in Parafilm-sealed vials in a refrigerator. Sources of samples and procedures for standard and sample solution preparation are shown in Table 1.

HPTLC. Premium Purity silica gel $60 \mathrm{~F}_{254}$ plates $(20 \mathrm{~cm} \times$ 10 cm; Merck KGaA, Darmstadt, Germany; Catalog No. 1.05648.0001) were used as received without prewashing. Calibration curves were created by spotting 7.00, 9.00, 11.0, and $13.0 \mu \mathrm{L}$ of the $100 \%$ sample solution, representing $70-130 \%$ of the label value of the active pharmaceutical ingredient. Assays were carried out by applying $10.0 \mu \mathrm{L}$ of each sample solution in triplicate. A CAMAG (Wilmington, NC, USA) Linomat 4 was used for semi-automated bandwise standard and sample solution zone application. An application rate of $4 \mathrm{~s} / \mu \mathrm{L}$ was used for all solutions. The band length was $6 \mathrm{~mm}$, the table speed was $10 \mathrm{~mm} / \mathrm{s}$, the distance between bands was $4 \mathrm{~mm}$, the distance from the left edge of the plate was $17 \mathrm{~mm}$, and the distance from the bottom of the plate was $1 \mathrm{~cm}$. Mobile phases used to develop plates in a CAMAG twin trough chamber and their respective $R_{\mathrm{F}}$ values are listed in Table 2. Automated HPTLC-densitometry in the absorption-reflectance mode was performed using a CAMAG Scanner 3 controlled by winCATS software, with $4.00 \mathrm{~mm} \times 0.45 \mathrm{~mm}$ Micro slit dimensions and a $20 \mathrm{~mm} / \mathrm{s}$ scan rate. All drugs for which the methods are detailed in this paper quenched fluorescence of the phosphor indicator in the silica gel. All were scanned under $254 \mathrm{~nm}$ ultraviolet (UV) light from a

This is an open-access article distributed under the terms of the Creative Commons Attribution-NonCommercial 4.0 International License (https://creativecommons.org/licenses/by-nc/4.0/), which permits unrestricted use, distribution, and reproduction in any medium for non-commercial purposes, provided the original author and source are credited, a link to the CC License is provided, and changes - if any - are indicated. 
Table 1. Preparation of $100 \%$ standard and $100 \%$ sample solutions

Pharmaceutical product
Amlodipine besylate (13.9 $\mathrm{mg}^{b}$;
Cipla Ltd., Mumbai, India)
Cefpodoxime proxetil (261 $\mathrm{mg}^{c}$; Pharma
International Co., Amman, Jordan)

Cetirizine 2HCl (10 mg; Square Pharmaceuticals Ltd., Dhaka, Bangladesh) Diclofenac sodium (50 mg; Zenufa Laboratories (T) Ltd., Dar es Salaam, Tanzania)

Diclofenac sodium (100 mg; Sichuan Huaxin Pharmaceutical Co., Ltd.,

Leshan, China)

Efavirenz (600 mg; Hetero Drugs Ltd., Hyderabad, India)

Mefenamic acid (500 mg; Blue Cross Laboratories Ltd., Mumbai, India)

Atovaquone + proguanil $\mathrm{HCl}$ (250 mg + 100 mg; Glaxo Wellcome S.A., Aranda de Duero, Spain)

$100 \%$ standard solution

$1.39 \mu \mathrm{g} 10.0 \mu \mathrm{L}^{-1}$ : dissolve $139 \mathrm{mg}$ standard

(Sigma-Aldrich, St. Louis, MO, USA, No. PHR1185)

in $100 \mathrm{~mL}$ methanol, then dilute $1.00 \mathrm{~mL}$ with $9.00 \mathrm{~mL}$ methanol

$1.00 \mu \mathrm{g} 10.0 \mu \mathrm{L}^{-1}$ : dissolve $100 \mathrm{mg}$ standard (USP, Rockville, MD, USA, Cat. No. 1098027) in $100 \mathrm{~mL}$ methanol, then dilute $1.00 \mathrm{~mL}$ with $9.00 \mathrm{~mL}$ methanol

$10.0 \mu \mathrm{g} 10.0 \mu \mathrm{L}^{-1}$ : dissolve $100 \mathrm{mg}$ standard (Sigma-Aldrich, No. PHR1656) in $100 \mathrm{~mL}$ methanol $1.00 \mu \mathrm{g} 10.0 \mu \mathrm{L}^{-1}$ : dissolve $100 \mathrm{mg}$ standard (Sigma-Aldrich, No. PHR1144) in $100 \mathrm{~mL}$ methanol, then dilute $1.00 \mathrm{~mL}$ with $9.00 \mathrm{~mL}$ methanol

$1.00 \mu \mathrm{g} 10.0 \mu \mathrm{L}^{-1}$ : dissolve $25.0 \mathrm{mg}$ standard (Sigma-Aldrich, No. SML0536) in $100 \mathrm{~mL}$ methanol, then dilute $2.00 \mathrm{~mL}$ with $3.00 \mathrm{~mL}$ methanol

$0.500 \mu \mathrm{g} 10.0 \mu \mathrm{L}^{-1}$ : dissolve $125 \mathrm{mg}$ standard (Sigma-Aldrich, No. 92574) in $100 \mathrm{~mL}$ methanol, then dilute $1.00 \mathrm{~mL}$ with $24.0 \mathrm{~mL}$ methanol $1.00 \mu \mathrm{g} 10.0 \mu \mathrm{L}^{-1}$ (atovaquone): dissolve $100 \mathrm{mg}$ standard (Sigma-Aldrich, No. PHR1591) in $100 \mathrm{~mL}$ methanol-acetone $(3: 1, v / v)$, then dilute $1.00 \mathrm{~mL}$ with $9.00 \mathrm{~mL}$ methanol-acetone $(3: 1, v / v)$

$0.400 \mu \mathrm{g} 10.0 \mu \mathrm{L}^{-1}$ (proguanil $\mathrm{HCl}$ : dissolve $100 \mathrm{mg}$ standard (Sigma-Aldrich, No. LR117301) in $100 \mathrm{~mL}$ methanol-acetone $(3: 1, v / v)$, then dilute $1.00 \mathrm{~mL}$ with $24.0 \mathrm{~mL}$ methanol-acetone $(3: 1, v / v)$

${ }^{a}$ Concentrations indicated for $100 \%$ sample solutions are theoretical concentrations.

${ }^{b_{\text {}}}$ The tablet contained an equivalence of $10.0 \mathrm{mg}$ amlodipine free base, so the amount of amlodipine besylate is $10.0 \mathrm{mg} \div 408.879 \mathrm{~g} / \mathrm{mol}$ (molecular weight of the free base $) \times 567.05 \mathrm{~g} / \mathrm{mol}$ (molecular weight of the besylate) $=13.9 \mathrm{mg}$.

${ }^{c}$ The tablet contained an equivalence of $200 \mathrm{mg}$ cefpodoxime free base, so the amount of cefpodoxime proxetil is $200 \mathrm{mg} \div 427.45 \mathrm{~g} / \mathrm{mol}$ (molecular weight of the free base $) \times 557.593 \mathrm{~g} / \mathrm{mol}($ molecular weight of the proxetil) $=261 \mathrm{mg}$.

Table 2. Mobile phases used in the development of plates for the analyses of pharmaceutical products containing amlodipine besylate, cefpodoxime proxetil, diclofenac sodium, efavirenz, mefenamic acid, and atovaquone + proguanil $\mathrm{HCl}$

\begin{tabular}{lcc}
\hline Pharmaceutical product & Mobile phase $^{a}$ \\
\hline Amlodipine besylate & Methanol-toluene-glacial acetic acid-water $(26: 6: 4: 4)$ \\
Cefpodoxime proxetil & Toluene-methanol-ethyl acetate $(20: 4: 16)$ & 0.74 \\
Cetirizine $2 \mathrm{HCl}$ & Ethyl acetate-methanol-ammonia $(28: 6: 4)$ \\
Diclofenac sodium & Ethyl acetate-methanol-acetone $(30: 9: 1)$ \\
Efavirenz & Toluene-methanol-ethyl acetate $(28: 8: 4)$ \\
Mefenamic acid & Toluene-ethyl acetate-glacial acetic acid (30:10:2) \\
Atovoquone & Acetone-methanol-glacial acetic acid $(30: 10: 1.1)$ \\
Proguanil HCl & Acetone-methanol-glacial acetic acid $(30: 10: 1.1)$ \\
$\quad$ & \\
\hline
\end{tabular}

deuterium lamp except amlodipine besylate, which was scanned as fluorescent zones under $366 \mathrm{~nm}$ UV light from a mercury lamp. The winCATS software created two calibration curves for each analysis using linear and second order polynomial regressions of the scan areas versus applied weights of standards. Sample weights were interpolated from calibration curves based on the bracketed scan areas of the samples. Spectral comparison was used to test peak purity and identity. Validation of the developed methods was performed using standard addition by spiking at 50,100, and $150 \%$ levels as described by Popovic and Sherma [3].

\section{Results}

Assay results of the seven pharmaceutical products are displayed in Table 3, all of which were between the 85 and $115 \%$ specification limits of the label value as specified by the model process guidelines except for cefpodoxime proxetil. However, good validation data for this drug confirmed the accuracy of these assays. As required by the model process, $r$-values of calibration curves for assays and validations and those of peak purity and peak identity were at least 0.99 . Results of validation by standard addition are listed in Table 4 , in which recoveries were between $95 \%$ and $105 \%$. Relative standard deviations (RSDs) for assays and validations were no greater than $3 \%$, which complies with the model process. The preferred regression mode for assays and validation of each pharmaceutical product was selected based on the best results in terms of higher calibration curve $r$-value, assay and validation recoveries closer to $100 \%$, and lower RSDs.

Previously published transferred Minilab methods for azithromycin dihydrate and cephalexin were used to analyze a new product of each drug. The exact procedures published earlier were followed, except that instead of using primary standards of the two drugs from Sigma-Aldrich, previously analyzed tablets of azithromycin dihydrate (Shelys Pharmaceuticals Ltd., Dar es Salaam, Tanzania) and cephalexin (North China Pharmaceutical Hebei Huamin Pharma Co., Ltd., Shijiazhuang, China) were used, respectively, as secondary standards for the analysis of Azibial-500 azithromycin dihydrate tablets (Bafna 
Table 3. Assay results for pharmaceutical products containing amlodipine besylate, cefpodoxime proxetil, diclofenac sodium, efavirenz, mefenamic acid, and atovaquone + proguanil $\mathrm{HCl}$

\begin{tabular}{|c|c|c|c|c|c|c|c|}
\hline \multirow[t]{2}{*}{ Pharmaceutical product } & \multirow[t]{2}{*}{ Regression mode } & \multicolumn{2}{|c|}{ Tablet 1} & \multicolumn{2}{|c|}{ Tablet 2} & \multicolumn{2}{|c|}{$\begin{array}{c}\text { Tablet } 3 \\
\end{array}$} \\
\hline & & Assay (\%) & RSD (\%) & Assay (\%) & $\mathrm{RSD}(\%)$ & Assay (\%) & RSD (\%) \\
\hline Amlodipine besylate & Polynomial & 103 & 0.206 & 102 & 1.27 & 104 & 1.60 \\
\hline Cefpodoxime proxetil & Linear & 121 & 1.08 & 125 & 1.74 & 131 & 1.39 \\
\hline Cetirizine $2 \mathrm{HCl}$ & Linear & 114 & 3.00 & 111 & 1.13 & 107 & 0.962 \\
\hline Diclofenac sodium (50 mg) & Linear & 96.1 & 2.08 & 94.8 & 1.01 & 94.0 & 1.11 \\
\hline Diclofenac sodium (100 mg) & Linear & 103 & 0.443 & 104 & 1.30 & 105 & 1.24 \\
\hline Efavirenz & Linear & 106 & 1.62 & 107 & 1.69 & 107 & 2.29 \\
\hline Mefenamic acid & Polynomial & 90.5 & 0.536 & 107 & 1.03 & 94.7 & 2.13 \\
\hline Atovaquone & Polynomial & 98.9 & 2.79 & 102 & 2.06 & 115 & 0.654 \\
\hline Proguanil $\mathrm{HCl}$ & Polynomial & 108 & 1.52 & 107 & 0.131 & 111 & 0.957 \\
\hline
\end{tabular}

Table 4. Validation results for pharmaceutical products containing amlodipine besylate, cefpodoxime proxetil, diclofenac sodium, efavirenz, mefenamic acid, and atovaquone + proguanil $\mathrm{HCl}$

\begin{tabular}{|c|c|c|c|c|c|c|c|}
\hline \multirow[t]{2}{*}{ Pharmaceutical product } & \multirow[t]{2}{*}{ Regression mode } & \multicolumn{2}{|c|}{$50 \%$ spike } & \multicolumn{2}{|c|}{$100 \%$ spike } & \multicolumn{2}{|c|}{$150 \%$ spike } \\
\hline & & $\operatorname{Rec}^{a}(\%)$ & $\operatorname{RSD}(\%)$ & $\operatorname{Rec}(\%)$ & RSD $(\%)$ & $\operatorname{Rec}(\%)$ & RSD (\%) \\
\hline Amlodipine besylate & Polynomial & 102 & 0.893 & 100 & 0.902 & 99.1 & 1.50 \\
\hline Cefpodoxime proxetil & Linear & 96.1 & 1.18 & 100 & 0.890 & 100 & 1.17 \\
\hline Cetirizine $2 \mathrm{HCl}$ & Linear & 105 & 0.850 & 104 & 0.889 & 100 & 2.42 \\
\hline Diclofenac sodium (50 mg) & Linear & 99.6 & 3.36 & 102 & 1.06 & 101 & 1.09 \\
\hline Diclofenac sodium (100 mg) & Linear & 100 & 1.09 & 99.3 & 1.57 & 95.0 & 1.94 \\
\hline Efavirenz & Linear & 104 & 2.76 & 103 & 2.76 & 104 & 1.21 \\
\hline Mefenamic acid & Polynomial & 99.8 & 1.93 & 98.1 & 0.811 & 102 & 1.26 \\
\hline Atovaquone & Polynomial & 101 & 0.750 & 102 & 1.03 & 99.5 & 1.50 \\
\hline Proguanil $\mathrm{HCl}$ & Polynomial & 101 & 1.34 & 99.9 & 0.979 & 104 & 0.678 \\
\hline${ }^{a} \operatorname{Rec}=$ Recovery & & & & & & & \\
\hline
\end{tabular}

Pharmaceuticals Ltd., Chennai, India) and Aurocef-250 cephalexin capsules (Aurobindo Pharma Ltd., Hyderabad, India). Assay values for triplicate analyses of three different tablets averaged 110,102 , and $96.1 \%$ for azithromycin dihydrate and $97.8,104$, and $106 \%$ for cephalexin, all of which were within the $85-115 \%$ guideline for acceptable assay results in the model process.

\section{Discussion}

The direct transfer of a TLC screening method to an HPTLC-densitometry method according to the model process involves the use of the same solvents in sample and standard solution preparation, the application of the same weights in $10.0 \mu \mathrm{L}$ of $100 \%$ standard and sample solutions as in $2.00 \mu \mathrm{L}$ in the Minilab method, and the use of the same mobile phase and detection mode. The Minilab method for amlodipine besylate (Minilab manual Volume II, Supplement 2017, Method 6.91, pp. 4-7) could be directly transferred based on these parameters

For the transfer of the cefpodoxime proxetil Minilab method (Volume II, Supplement 2017, Method 6.92, pp. 8-11), both the applied weight and the mobile phase were changed. The applied weight was changed to $0.800 \mu \mathrm{g}$ instead of $2.00 \mu \mathrm{g}$ in the Minilab manual to achieve better scan results. Five mobile phases were tested in total, namely, toluene-methanol (20:20, from the Minilab method), ethyl acetate-methanol (30:10) [7], toluene-ethyl acetate-methanol (20:16:4) [8], methanol-water (20:20) [9], and ethanol-water (20:20) [9]. Among these, tolueneethyl acetate-methanol produced the best peak shape and highest $r$-value and was chosen for use. All the assays of this drug were over $120 \%$ of the label value, but the accuracy of the results was verified by the validation data.

The cetirizine $2 \mathrm{HCl}$ Minilab method (Volume II, Supplement 2018, Method 6.97, pp. 4-7) specifies the use of an iodine vapor staining step for zone detection. Detection was simplified in the densitometry method by eliminating the need for this reagent by increasing the applied weight to $10.0 \mu \mathrm{g}$ from $2.50 \mu \mathrm{g}$ to obtain sufficiently dark fluorescence quenching zones for scanning at $254 \mathrm{~nm}$. The mobile phase was changed to the one reported by Makhija and Vavia [10], because the original mobile phase for the Minilab method, methanol-ethyl acetate-toluene (14:4:2), produced zones with long, upward tails rather than the more compact zones with the new mobile phase, ethyl acetate-methanol-ammonia (28:6:4). In the Minilab screening method, iodine vapor detection could also be eliminated by applying higher weights of drug sample and standard and thereby giving increased intensity of the spots under $254 \mathrm{~nm}$ UV light.

For the transfer of the diclofenac Minilab method (Volume II, Supplement 2018, Method 6.99, pp. 12-15), the spotted weight was lowered to $1.00 \mu \mathrm{g}$ because the weight of $2.50 \mu \mathrm{g}$ in the Minilab protocol was too high for successful densitometry. This method was applied successfully to both 50 and $100 \mathrm{mg}$ tablets.

For the transfer of the efavirenz Minilab method (Volume II, Supplement 2017, Method 6.95, pp. 20-23), the only modification was the applied weight, which was changed to $1.00 \mu \mathrm{g}$ as opposed to $2.00 \mu \mathrm{g}$ in order to obtain less dark bands and higher $r$-value for the densitometry calibration curve.

Transfer of the mefenamic acid Minilab method (Volume II, Supplement 2018, Method 6.100, pp. 16-19) required modifications of the applied weight and the standard and sample solution solvent. The applied weight of $2.50 \mu \mathrm{g}$ in the Minilab method was reduced to $0.500 \mu \mathrm{g}$ to achieve an acceptable $r$-value for the densitometry calibration curve. The Minilab method uses methanol-ammonia (23:2) as the solvent for the stock solutions and methanol for dilution to prepare the working solutions. It was found that the use of methanol to prepare both the stock and working solutions gave excellent densitometry results.

The atovaquone + proguanil $\mathrm{HCl}$ simultaneous Minilab method (Volume II, Supplement 2010, Method 6.43, pp. 8-11) could not be directly transferred because the applied weights in the Minilab protocol were too high for successful densitometry. The applied weight was lowered to $1.00 \mu \mathrm{g}+0.400 \mu \mathrm{g}$ to obtain satisfactory calibration curves. The Minilab method mobile phase was modified by increasing the amount of acetic acid by $0.1 \mathrm{~mL}$ to $1.1 \mathrm{~mL}$. This mobile phase decreased the $R_{\mathrm{F}}$ value of atovaquone and moved it further away from the 


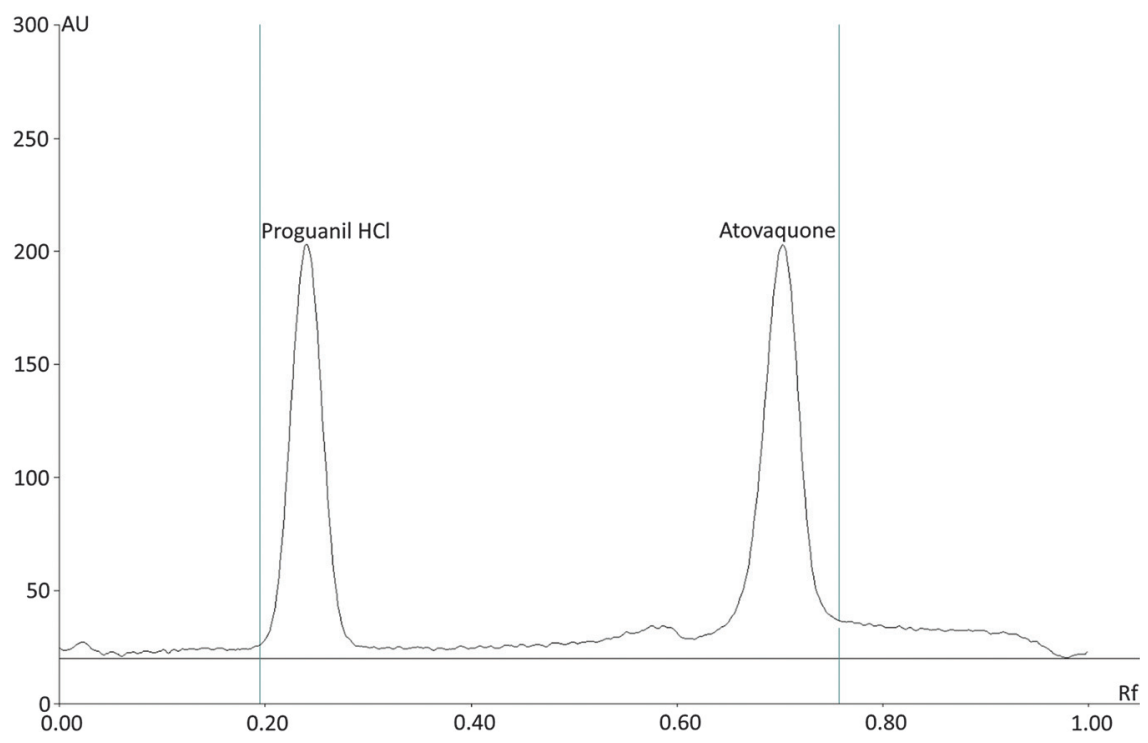

Figure 1. Densitogram of $10.0 \mu \mathrm{L}$ of atovaquone + proguanil $\mathrm{HCl} 100 \%$ sample solution, showing peaks for atovaquone $\left(R_{\mathrm{F}}: 0.70\right)$ and proguanil $\mathrm{HCl}\left(R_{\mathrm{F}}: 0.24\right)$

mobile phase front. It also gave good drug separation and zone scans (Figure 1).

\section{Conclusion}

The previously developed model process was applied to the transfer of seven Minilab TLC screening methods for pharmaceutical products containing eight different drugs to HPTLCdensitometry methods. Depending on the applications of the methods described in this paper, they should be fully validated for parameters such as accuracy, precision (repeatability and intermediate precision), specificity, linearity, range, and robustness under relevant guidelines such as those described by the International Conference on Harmonization [11] or subjected to an interlaboratory study [12] to prove that they are suitable for their intended purpose by users.

Acknowledgments. The authors thank Thomas Layloff, Senior Quality Assurance Advisor, Supply Chain Management System (SCMS), Arlington, VA, USA, for his assistance in designing the model process and its application to the analysis of pharmaceutical products, and for arranging delivery of drug samples supplied by the Dar es Salaam, Tanzania, Office of
SCMS. We also thank Dr. Gerd Battermann, Head of Instrumental Analytics Franchise, Merck KGaA, Darmstadt, Germany, for providing the Premium Purity HPTLC plates used in our experiments. Bingsong Zeng and Yiru Gu were supported by the Lafayette College EXCEL Scholar Program.

\section{References}

1. O'Sullivan, C.; Sherma, J. Acta Chromatogr. 2012, 24, 241-252.

2. Lianza, K.; Sherma, J. J. Liq. Chromatogr. Relat. Technol. 2013, 36, 2446-2462.

3. Popovic, N.; Sherma, J. Acta Chromatogr. 2014, 26, 615-623.

4. Global Pharma Health Fund e.V., http://www.gphf.org (accessed July 1, 2018).

5. Zhang, D.; Armour, E.; Sherma, J. Acta Chromatogr. 2017, 29, $484-486$.

6. Armour, E.; Sherma, J. J. Liq. Chromatogr. Relat. Technol. 2017, 40, 282-286.

7. Zhang, D.; Strock, J.; Sherma, J. J. Liq. Chromatogr. Relat. Technol. 2016, 39, 277-280.

8. Nguyen, K.; Zhang, D.; Sherma, J. Trends Chromatogr. 2017, 11, 12-17.

9. Sharma, S.; Singh, S.; Baghel, S. J. Environ. Res. Dev. 2006, 1, 46-48.

10. Makhija, S. N.; Vavia, P. R. J. Pharm. Biomed. Anal. 2001, 25, 663-667.

11. Ferenczi-Fodor, K.; Vegh, Z.; Nagy-Tuak, A.; Renger, B.; Zeller, M J. AOAC Int 2001, 84, 1265-1276.

12. Kaale, E.; Risha, P.; Reich, E.; Layloff, T. P. J. AOAC Int. 2010, 93, 1836-1843. 